\title{
A REPERCUSSÃO dAS MORTES DE GERMÂNICO E DRUSO NA ATUAC̣ÃO JURÍDICA DE TIBÉRIO SEGUNDO OS ANAIS DE TÁCITO
}

Dominique Monge Rodrigues de SOUZA

(D) dominiquemonge@hotmail.com

Universidade Estadual Paulista, Franca, SP, Brasil

The repercussion of the deaths of Germanicus and Drusus in Tiberius' legal action according to the Annals of Tacitus

\section{RESUMO}

Os Livros I-VI dos Anais, escritos por Tácito, legaram importantes vestígios sobre o estabelecimento da dinâmica entre o Senado Romano e o imperador Tibério no âmbito jurídico. Com base no levantamento dos processos relatados nesses livros, observamos um crescimento no número de acusações de maiestas e repetundae relatadas no decorrer dos Livros III e IV. Estes livros dedicam-se aos contextos posteriores às mortes de Germânico e Druso, ambos filhos, o primeiro por adoção, e possíveis sucessores de Tibério. Neste artigo, a partir da análise das acusações de maiestas e repetundae, propomos o estudo da repercussão das mortes desses personagens históricos na narrativa da atuação jurídica de Tibério e da relação deste princeps com a corte senatorial. Desse modo, através da análise dessas acusações, objetivamos compreender o desenvolvimento das práticas jurídicas do Senado e do princeps, assim como a argumentação de Tácito em torno da gradual degradação do Principado de Tibério.

Palavras-chave: Principado Romano, Cortes de Justiça, Senado, Tibério, Tácito.

\begin{abstract}
The Books I-VI of the Annals, written by Tacitus, bequeathed important traces about the establishment of the dynamic between the Roman Senate and Tiberius in the legal sphere. Based on the survey of the lawsuits reported in these books, we observed an increase in the number of maiestas and repetundae charges reported throughout Books III and IV. These books are dedicated to the contexts after the deaths of Germanicus and Drusus, both sons, the first by adoption, and possible successors of Tiberius. In this article, through the analysis of the maiestas and repetundae charges, we propose the study of the repercussion of the deaths of these historic characters in the narrative of Tiberius' legal action and in the relation of this princeps with the senatorial court. Thus, through the analysis of these accusations, we aim to understand the development of the Senate's and princeps' legal practices, as well as Tacitus' argumentation around the gradual degradation of the Principate of Tiberius.
\end{abstract}

Keywords: Roman Principate, Law Courts, Senate, Tiberius, Tacitus. 


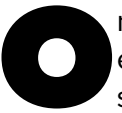
relato de acusações ${ }^{1}$ e de disputas em cortes de justiça foi amplamente empregado por autores do período do Principado Romano na construção de suas narrativas acerca dos governos dos imperadores. Autores, como Tácito, usaram em seus escritos estratégicas retóricas que visavam (des)qualificar os governos imperiais. Assim, as informações legadas sobre cada processo foram apresentadas de modo a exaltar ou depreciar a atuação de um determinado princeps na aplicação das leis, no julgamento e na sua relação com o Senado.

Especificamente, na obra Anais, escrita por Tácito entre 115-120 d.C., foram preservados os relatos de processos sediados no governo de Augusto (27 a.C. - 14 d.C.), Tibério (14-37 d.C.), Cláudio (41-54 d.C.) e Nero (54-68 d.C.). Tácito menciona nessa obra diversos processos sediados no Senado, perante o Imperador, nas quaestiones perpetuae ${ }^{2}$, dentre outras cortes de justiça.

Nos Livros I-VI do Anais, dedicados ao governo do imperador Tibério, foi possível identificar cento e quatorze processos de diversas naturezas, como por exemplo, adultério (Ann. I 53; II 50; III 22; 24; 38; IV 42; 52; VI 23; 25; 29; 40), cobrança de dívidas (Ann. II 34), assassinato (Ann. II 64-67; IV 22), prática de magia (Ann. II 32). Dentre eles, setenta e um correspondem às acusações de maiestas e/ou repetundae. Como veremos nesse artigo, essas acusações têm notoriamente um caráter político, relacionado à administração e ao comando do império e foram utilizadas como meio de contenção dos opositores.

O crime de repetundae (crimen repetundarum) era previsto em diversas leis do período republicano, a saber: Lex Calpurnia de repetundis (149 a.C.); Lex Acilia de repetundarum (122 a.C.); Lex Servilia Caepionis de repetundis (106 a.C.); Lex Servilia Glauciae de repetundis (101 a.C.); Lex Cornelia de repetundis (81 a.C.) e Lex Iulia repetundarum, (provavelmente proposta por Júlio César em 59 a.C.). Esse conjunto de leis, de modo geral, criminalizava o recebimento de valores através de suborno ou extorsão por parte dos governadores de províncias e de seus funcionários durante o exercício de suas funções. Cada uma dessas leis implementou mudanças, seja nos procedimentos de julgamento (como as normas para composição do júri), seja na definição do crime e nas punições estabelecidas que permaneceram sendo empregadas durante o Principado.

O crime de maiestas (crimen maiestatis ou maiestatis minuta populi romani), por sua vez, durante o Principado, era definido pela Lex de lulia maiestatis, proposta, provavelmente, por Júlio César ${ }^{3}$. Há poucas informações acerca dos comportamentos criminalizados por essa lei, mas é possível inferir, através dos vestígios existentes, que durante o Principado esta acusação era direcionada aos indivíduos (ou mesmo comunidades) que praticavam ações interpretadas como ameaçadoras à Roma, ao imperador e aos membros da família imperial. Provavelmente, as definições desta ofensa, desde o período republicano, eram amplas o suficiente para abarcar uma diversidade significativa de práticas, adaptáveis às necessidades políticas de determinado contexto. 
Dentre as setenta e uma acusações de maiestas e/ou repetundae identificadas nos seis primeiros livros, sete incorporaram acusações de crimen repetundarum ${ }^{4}$. Destas, apenas uma não foi acompanhada da acusação de maiestas, caso de Lucilius Capito (Ann. IV 15). Além de repetundae, acusações como adultério poderiam ser acompanhas por denúncias de maiestas visando o agravamento da acusação, da pena e/ ou beneficiar os acusadores, como por exemplo, através do confisco dos bens dos condenados e entrega de parte desses bens aos delatores.

A inserção de maiestas visando o agravamento das denúncias foi uma prática atribuída por Tácito ao Principado de Augusto. De modo mais específico às acusações de adultério de Júlia, a Velha, em 2 a.C. (Ann I 53; III 24; IV 44; 71), filha de Augusto, Julia, a Jovem, em 8 d.C. (Ann. III 24; IV 71), filha da primeira, e seus respectivos cúmplices Sempronius Gracchus (Ann. I 53), lullus Antonius (Ann. IV 44) e D. Iunius Silanus (Ann. III 24; IV 7). Além destes acusados, Tácito narra a acusação de Cassius Severus (Ann. I 72), denunciado por escritos difamatórios, prática já prevista na Lex Cornelia de inuriis (81 a.C.). A acusação de Cassius Severus acrescida da acusação de maiestas levou o condenado ao exílio. Essa prática de agravamento das acusações foi amplamente empregada durante o governo de Tibério, como discorreremos a seguir.

Assim, apesar de dedicar o primeiro livro de Anais ao governo de Tibério, Tácito aponta diversos acontecimentos do Principado de Augusto. O primeiro governo imperial foi delineado por Tácito como um período de crescente intervenção do princeps em questões jurídicas e interligado por este autor à construção da narrativa do Principado de Tibério e aos precedentes jurídicos por ele aplicados. Desse modo, os processos ocorridos no período de Augusto correspondem a parte significativa do Livro I de Anais. Os primeiros anos de Tibério, por sua vez, foram narrados por este autor de modo a enfatizar a participação do Senado e os embates entre os senadores e o princeps.

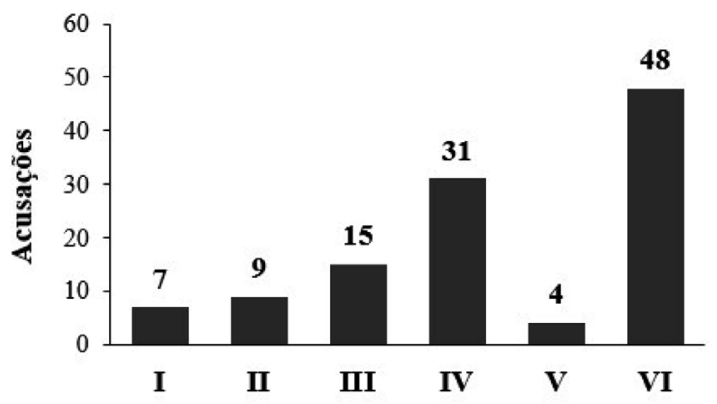

Livros

Gráfico 01 - Distribuição das acusações judiciais nos Livros I-VI dos Anais de Tácito ${ }^{5}$ 
Dos sete processos gerais (gráfico 01) mencionados por Tácito no Livro I, quatro ocorreram no período de Augusto 6 e três foram denúncias de profanação de estátuas desse imperador.7 Estes últimos três processos ocorreram no ano seguinte à morte de Augusto e os acusados foram absolvidos por Tibério. Portanto, acreditamos que Tácito procurou neste primeiro livro interligar, através das acusações de maiestas, o governo de Augusto ao de Tibério e legar, no decorrer dos livros dedicados a esse último governo, a história de um princeps que gradativamente deixava de aplicar as leis de acordo como os precedentes atribuídos a Augusto.

Além disso, se inicialmente, desconsiderarmos, o Livro V - uma vez que, não é possível precisar o número total de casos deste livro, em razão da sua preservação fragmentada ${ }^{8}$ - constataremos que a quantidade de acusações judiciais relatadas cresce significativamente no decorrer dos livros dos Anais dedicados ao período de Tibério. Em nossa perspectiva, a crescente inserção de processos judiciais foi utilizada por este autor como suporte para sua crítica à atuação de Tibério e de outros atores políticos que circundavam o poder imperial.

De acordo com Eleanor Cowan (2009, p. 181, 206), Tácito seleciona e, em certos casos, constrói cuidadosamente incidentes que atraem a atenção para a dependência de Tibério em relação aos precedentes de Augusto. O que pode ser observado pela notável preocupação deste historiador em explicar os requisitos para sucessão imperial - geralmente atrelados à eliminação de rivais - e pela necessidade de sistematizar as realizações de Augusto. Segundo ela (COWAN, 2009, p. 181), essa sustentação do segundo Principado nos precedentes do primeiro não foi apenas construção de Tácito, mas também se configurou como uma estratégia de Tibério para explicar e negociar sua posição como sucessor, conforme legado em outras documentações sobre esse período.

Esses aspectos da escrita taciteana se tornam mais evidentes e relevantes para nosso estudo se observarmos a disposição e sequência narrativa das denúncias de maiestas e/ou repetundae nos Livros I-VI dos Anais, especificamente.

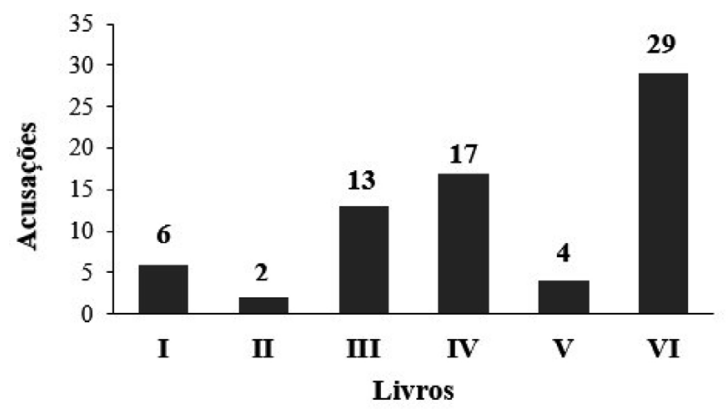

Gráfico 02 - Processos que não incluem acusações de maiestas ou repetundae em Anais I-VI, Tácito 
Com exceção do Livro II, o gráfico 02 demonstra que a quantificação e distribuição das acusações de maiestas e/ou repetundae tendem a seguir o padrão de ordenação apresentado pelo gráfico 01 , no qual alocamos os cento e quatorze processos judiciais mencionados por Tácito. No Livro II, no entanto, observamos uma queda no número de acusações de maiestas e/ou repetundae. Dos nove casos gerais (gráfico 1) levantados no Livro II, apenas duas acusações são de maiestas $^{9}$ e nenhuma incluiu repetundae entre as ações julgadas.

A partir do Livro II, Tácito passa a relatar de modo mais efetivo a atuação de Tibério perante a corte senatorial, dando cada vez mais relevância para as acusações de maiestas que ocorreram durante este Principado.

Este senador romano descreve os primeiros anos do Principado de Tibério, como um período no qual o princeps interfere constantemente na atuação da corte senatorial e em outras cortes de justiça na cidade de Roma. As atividades na corte imperial perdem espaço na narrativa taciteana, quando comparadas com o relato do governo de Augusto. Casos que antes eram julgados pelo imperador, passam a ser debatidos na corte senatorial, apesar de contarem com intensa interferência de Tibério. Porém, é interessante notar que estas primeiras interferências tenderam a beneficiar os acusados. Dos cinco processos de maiestas ocorridos nesse período (14-17 d.C.), quatro contaram com a absolvição ${ }^{10}$ deste crime resultante da atuação do princeps.

Assim, Tácito nos apresenta, nos dois primeiros livros, um Tibério que procurou atrelar as suas atividades judiciais à corte senatorial, apontando, desse modo, para um fortalecimento da atividade judicial do Senado neste segundo Principado.

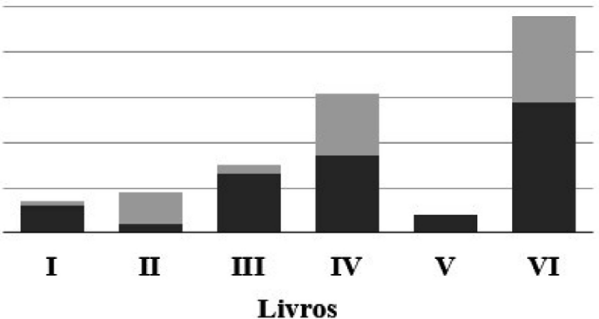

Livros
Processos que não incluem acusações de maiestas ou repetunda

- Acusados de maiestas e/ou repetundae

Gráfico 03 - Gráfico com a distribuição das acusações nos Livros I-VI dos Anais de Tácito

No gráfico 03, que dispõe a sobreposição dos dados dos gráficos anteriores, observamos a predominância das acusações de maiestas e/ ou repetundae no decorrer dos Livros III e IV. 
Também no gráfico 03, nos deparamos com a problemática em torno do Livro $\mathrm{V}$ e sua preservação fragmentada, como declaramos. Em seguida, no Livro VI, observamos o crescimento do número total de processos judiciais e a manutenção da predominância dos casos que incluem acusações de maiestas e/ou repetundae.

Porém, o elevado número no Livro VI incorporado em "Processos que não incluíam acusações de maiestas ou repetundae" se deve aos diversos casos que não tiveram as suas acusações mencionadas por Tácito e, portanto, não foram incorporados por nós na seleção de processos de maiestas e/ ou repetundae. Dos dezenove casos classificados naquela categoria não é possível determinar, através de nossa documentação, a acusação em dez deles.

Tácito não apenas associou o desenvolvimento dessas práticas jurídicas do Senado e do princeps ao seu argumento da degradação gradual do Principado deste imperador, mas também interligou o aviltamento desse governo às sucessivas mortes de indivíduos próximos a Tibério (WOODMAN, 2017, p. 49). Germânico, morto em 19 d.C. (Ann. II 79), havia sido adotado por Tibério logo após a adoção deste por Augusto; Druso (Ann. IV 8), filho de Tibério com Vipsânia, morto em 23 d.C.; Lívia (Ann. V 1), mãe de Tibério e viúva de Augusto, falecida em 29 d.C.; e, por fim, Sejano (morte em 31 d.C.), prefeito da guarda pretoriana e político romano muito influente em razão das relações interpessoais"11 estabelecidas com o princeps. À cada um desses atores políticos, Tácito atribuiu um papel ativo no comando do Império junto a Tibério. Estes personagens, por sua vez, dividem espaço na narrativa taciteana com outros grupos que visavam também ocupar lugar na distribuição e compartilhamento dos poderes.

Neste artigo, iremos nos dedicar ao estudo das acusações presentes no Livro III e IV, voltadas à narrativa dos eventos posteriores à morte de Germânico, em 19 d.C., e de Druso, em 23 d.C. Será nosso fito compreender a repercussão da morte destes personagens no relato de Tácito a propósito da atuação jurídica de Tibério.

\section{Acusações após a morte de Germânico (19 d.C.)}

Tácito não apresenta um padrão estabelecido para a narrativa dos processos. Os tipos de informações fornecidas também são variáveis. Não são todos os processos nos quais ele nomeia os acusadores, os acusados ou acusadas, as ofensas denunciadas, as condenações, penas, testemunhas e os senadores envolvidos nos debates a respeito da culpabilidade e das penalidades.

Os desafios impostos à localização das acusações judiciais e à definição da corte de justiça responsável decorrem dos diferentes modos a partir dos quais Tácito nos apresenta essas demandas, assim como em virtude das informações ora fornecidas, ora omitidas. De modo geral, as descrições dos processos se restringem a no máximo três capítulos, consideradas as exceções ${ }^{12}$. Parte significativa dos casos levantados (quarenta e quatro acusações) é narrada em apenas um capítulo, muitas vezes reunidos com o relato de outras demandas judiciais.

Leanne Bablitz (2015), propõe uma contagem por linhas dedicadas a cada processo, considerando apenas o conteúdo relacionado ao julgamento. Em seu levantamento, 
realizado em todos os livros preservados dos Anais, ela demonstrou que dos duzentos e vinte casos levantados, cinquenta e nove são retratados em menos de uma linha e noventa e quatro entre uma e quatro linhas (BABLITZ, 2015, p. 69). Dentre esses casos identificados por esta historiadora, o mais extenso é o que se refere às acusações do senador romano Cn. Calpurnius Piso (entre 80 e 84 linhas) (BABLITZ, 2015, p. 70).

Tácito relata no decorrer de Ann III 7-19 o processo deste senador implicado na morte de Germânico, herdeiro e filho adotivo de Tibério. Porém, podemos recuar a descrição dos eventos até Ann. II 43, onde encontramos o contexto que levou à condenação de $\mathrm{Cn}$. Piso.

No decorrer do Livro II, nos deparamos com as disputas entre Germânico e Cn. Piso em torno do comando da província da Síria (Ann. II 43; 53; 55-58; 69); o adoecimento e a morte de Germânico (Ann. II 69-73; 82-83); o levante de Cn. Piso visando recuperar o governo da província (Ann. II 74-80); a captura de Cn. Piso e o seu retorno à cidade de Roma para ser denunciado (Ann. II 81).

Essa contextualização que antecede o relato da acusação e do julgamento de $\mathrm{Cn}$. Piso é uma exceção quando comparada com os demais casos inseridos na obra taciteana. Além de sua conexão com a morte de Germânico, o destaque desta acusação de 20 d.C. pode estar atrelado à grande quantidade de informações legadas e acessíveis ${ }^{13}$ a Tácito na ocasião da escrita de Anais.

Como exposto, Tácito dedicou parte significativa do Livro II aos embates entre Germânico e Cn. Piso. A narrativa é iniciada com o relato da concessão do imperium maius e do comando das províncias "separadas pelo mar"14 a Germânico pelo Senado (Ann. II 43, 1). Posteriormente, este historiador romano discorre a propósito do afastamento de Creticus Silanus ${ }^{15}$ do governo da Síria (Ann. II 43,2) e a substituição deste por Cn. Piso (Ann. II 43, 4), em 17 d.C., a mando de Tibério.

Como legatus de Tibério na Síria, Cn. Piso não possuía o imperium proconsular, o que o colocava sob a autoridade de Germânico (DAMON, 1999, p. 150-151). Em 18 d.C., Germânico assumiu o consulado com Tibério, que ocupava este cargo pela terceira vez (Ann. II 53,1).

Tácito prossegue expondo a permanente rivalidade entre esses indivíduos, como a recusa de $C n$. Piso em levar legiões à Armênia, após ordens de Germânico (Ann. II 57,1-2), e a anulação ou alteração das ordens dadas por Germânico para o comando das legiões e cidades na Síria, dadas antes de sua partida para o Egito (Ann. II 59, 1). Na ocasião do retorno de Germânico, o autor de Anais inicia o relato do seu adoecimento, traçando elementos que direcionavam suas causas para Cn. Piso (Ann. II 69,3). Pouco antes de anunciar a morte de Germânico, Tácito se reporta a uma fala deste a seus amigos, em que acusava Piso e Plancina por seu envenenamento e sua possível morte (Ann. II 71).

Após a morte de Germânico (19 d.C.), Cn. Sentius, senador romano, assumiu o governo da Síria, conforme deliberação dos legatus imperiais e senadores presentes na província (Ann. II 74, 1). Vitellius e Veranius, por sua vez, membros do círculo de amigos de Germânico e responsáveis por empreenderem a acusação em Roma, solicitaram a 
Cn. Sentius o envio de Martina a Roma (Ann. II 74, 2), para que testemunhasse contra Cn. Piso e Plancina. Muito próxima a Plancina, Martina era conhecida, segundo Tácito, por seus supostos envenenamentos (Ann. II 74, 2). Cn. Sentius cumpriu a solicitação de Vittelius e Veranius, porém Martina morreu no trajeto para Roma (Ann III 7, 2).

Tácito nos conta também que Piso e Plancina comemoraram as notícias da morte de Germânico. Piso celebrou tal acontecimento realizando sacrifícios e demonstrando grande alegria, já Plancina o fez abandonando o luto pela morte de sua irmã, através da troca das vestimentas que trajava por outras de caráter festivo (Ann. II 75, 2).

Até este momento da narrativa, os eventos relatados demonstram que a acusação proposta por Vittelius e Veranius contra Cn. Piso envolvia apenas a morte de Germânico por envenenamento. Além da convocação de Martina, a fala de Marsus Vibius corrobora com esta perspectiva:

Quando estavam costeando Lycia e Pamphylia, se encontraram com as embarcações que levavam Agripina e, em um primeiro momento ambas as partes apresentaram as armas com ânimo para o ataque. Depois, por medo mútuo, não se passou de ofensas, e Marsus Vibius pronunciou para Piso que ele deveria ir para Roma defender sua causa. Ele respondeu ironicamente que iria quando o pretor responsável pelos envenenamentos fixasse o dia aos réus e aos acusadores. (Ann. II 79, 1).

Nesse trecho, $\mathrm{Cn}$. Piso faz referência a quaestio de sicariis et veneficis, tribunal permanente responsável pelo julgamento de acusações de envenenamento. Desse modo, Tácito indica que $\mathrm{Cn}$. Piso acreditava que seria acusado apenas pela morte de Germânico. Porém, no seu retorno à província, Cn. Piso intentou recuperar o comando da Síria, incitando o exército a sublevar e ocupar uma fortificação na Cilicia ${ }^{16}$ (Ann II 77). Essas ações compunham as acusações mais graves, como veremos em seguida. Vencido por Cn. Sentius (Ann. II 80), Cn. Piso foi enviado a Roma (Ann II 81, 2).

M. Calpurnius Piso, filho de Cn. Piso, antes da chegada de seu pai em Roma, se apresenta perante Tibério e seu filho Druso. De acordo com Tácito, M. Piso tinha esperanças de encontrar Druso satisfeito pela morte de um rival, o que não ocorreu.

Druso respondeu a Piso que se fossem certas as acusações, especialmente ele sentiria a dor, mas que preferia que fossem falsas e vãs e que a morte de Germânico não fosse fatal para ninguém. Isto foi dito abertamente e evitando segredo e não se duvidava de que Tibério havia ditado isto, visto que, sendo Druso, em geral, pouco astuto e complacente de sua juventude, procedia naquela ocasião com artes próprias de um ancião. (Ann. III 8, 2).

Nesse trecho, Tácito introduz o posicionamento que Tibério e Druso mantiveram durante o processo, contrário à expectativa de $M$. Calpurnius Piso, como delineado por nosso autor. Em diferentes momentos (Ann. II 43, 2, 4-5; 16; 17) de sua narrativa, Tácito sugeriu que $\mathrm{Cn}$. Piso e Plancina contavam com o apoio do princeps e de 
Lívia nas investidas contra Agripina, a Velha, e Germânico17. No entanto, nesta fala atribuída à Druso, Tácito adianta a recusa de Tibério em impedir o prosseguimento das investigações da morte de Germânico. Além disso, sinaliza para uma possível condenação à morte, caso comprovada a culpa de Cn. Piso.

O primeiro passo para a instauração de uma acusação perante a corte senatorial era apresentar as denúncias ao princeps ou para algum magistrado que pudesse convocar o Senado, normalmente o cônsul. De acordo com Richard J. A. Talbert (1984, p. 480), o acusador deveria solicitar autorização (postulatio) para apresentar a denúncia. Esta primeira solicitação no caso de $C n$. Piso foi empreendida, segundo Tácito (Ann. III 10, 1), por Fulcinius Trio. Contudo Vitellius e Veranius se opõem:

A ele [Fulcinius Trio] se opuseram Vittelius e Veranius e demais membros da comitiva de Germânico, alegando que Trio não fazia parte do assunto e que eles não compareciam como acusadores, mas como informantes e testemunhas dos fatos e para fazer presente os desejos de Germânico. (Ann. III 10, 1).

Nesse excerto, Tácito diferencia aqueles que atuam como acusadores visando ganhos próprios, e aqueles que agem motivados pelas obrigações previstas nas relações interpessoais, caso de Vittelius e Veranius.

Não havia um magistrado responsável pela instauração dos processos. Logo, as punições pelos crimes cometidos dependiam da iniciativa de algum indivíduo para apresentar a denúncia perante o magistrado responsável pelo tribunal. Esta característica da organização judicial romana salienta o papel relevante desses personagens para o combate de certas práticas criminosas, como as investigadas por nós neste artigo.

A relevância dos acusadores para punição de práticas criminosas data do período republicano. No entanto, como observado por Steven H. Rutledge (1999, p. 556), de modo geral, a historiografia tende a afirmar que houve um agravamento das delações com o início do governo do imperadores. Esse aspecto tem sido embasado na produção escrita desse período, principalmente nas obras de Plínio, o Jovem, e Tácito, que também afirmam o crescimento da agressividade da oratória nas cortes de justiça (RUTLEDGE, 1999, p. 556; 572). Contudo, para Rutledge (1999) os acusadores também eram atuantes nos tribunais republicanos, assim como também sua oratória era acompanhada de agressividade e apelo emocional da audiência. Esta agressividade e apelo emocional, tão criticados por nossos autores, eram características da accusatio e previstas nos manuais de retórica que preparavam oradores para atuarem perante cortes de justiça (RUTLEDGE, 1999, p. 562-565). Desse modo, apesar de não nos ser possível afirmar a existência do aumento da agressividade nas cortes de justiça e do número de acusações no Principado, quando comparado com a República, nos deparamos, nas obras de autores como Tácito, com críticas a respeito das atividades desses acusadores. Encontramos, ademais, advertências sobre o uso das condenações para o favorecimento das carreiras políticas e dos ganhos materiais 
Assim, a participação de Trio nesse processo, quando comparada com a de Vittelius e Veranius, delimita essa fronteira entre as acusações vistas como aceitáveis - ou seja, respaldadas em interesses que iam para além dos ganhos políticos e de bens - e aquelas condenáveis por nosso autor.

Em razão das alegações de Vittelius e Veranius expostas na citação anterior, Trio abandonou a denúncia das ações sobre a morte de Germânico e as ocorridas na Síria, porém foi autorizado a instaurar acusações (Ann. III 10,2) por ilegalidades cometidas por Cn. Piso, durante o seu governo da província Hispania (Tarraconensis) e que, possivelmente, envolveram crimen repetundarum (Ann. III 13).

Tácito também relata que foi solicitado - embora não mencione o autor do pedido - a Tibério que se encarregasse desse processo. Esta é a primeira vez nos Anais em que Tácito apresenta Tibério atuando como único juiz, no que compreendemos como corte do imperador, em um caso que envolveu crimes julgados de acordo com a Lex Maiestatis.

Não passava desapercebido para Tibério a magnitude deste inquérito [congnitionis] e a fama que o assolaria. Assim, em presença de alguns familiares, escutou as ameaças dos acusadores e os pedidos da outra parte, para logo devolver ao Senado o caso intacto. (Ann. III 10, 3).

Neste trecho, Tibério, após ouvir as acusações e a resposta da defesa, optou por transferir o julgamento do processo para a corte senatorial. Mais adiante no texto, Tácito menciona como os argumentos em torno da culpabilidade de $\mathrm{Cn}$. Piso pela morte de Germânico eram insuficientes para sua condenação.

A Síria era uma província imperial, logo o levante de Cn. Piso e sua tentativa de retomada da província deveriam ser julgados por Tibério. No entanto, a possível absolvição de $\mathrm{C}$. Piso pela morte de Germânico, em razão da falta de provas, era um dos riscos da resolução desse processo por Tibério. Desse modo, o princeps optou por remeter ao Senado a responsabilidade por este caso. A excepcionalidade deste processo foi um dos argumentos utilizados por Tibério para não julgá-lo, como veremos a seguir.

Com o retorno do processo à corte senatorial, Tácito descreve um discurso de Tibério (Ann. III 12), no qual o princeps procurou instruir o andamento do julgamento. Neste discurso, o princeps relembrou a relação de amicitia que o acusado possuía com Augusto, de quem foi legatus ${ }^{18}$ na província Hispania (Tarraconensis). Também instruiu a corte senatorial a se ater às condenações por crimes previstas em leis e não condenar apenas por inimizades [privatas inimicitias] (Ann. II 12, 2).

Perante o Senado, Cn. Piso foi defendido (Ann. III 11, 2) por seu irmão L. Piso ${ }^{19}$, Livineius Regulus ${ }^{20}$ e M. Aemilius Lepidus ${ }^{21}$. Tibério, no discurso retratado por Tácito e mencionado acima, afirma a excepcionalidade do caso, salientando a realização do julgamento perante a corte senatorial e não diante dos juízes, provavelmente se referindo à quaestio de sicariis et veneficis: "Apenas este privilégio teremos concedido 
a Germânico: que a investigação de sua morte se faça na cúria ao invés do fórum. Perante o Senado no lugar dos juízes. No restante, deve haver a mesma medida." (Ann. III 12, 7).

Trio inicia a acusação de $\mathrm{Cn}$. Piso, focando nos eventos ocorridos durante o proconsulado deste na Hispania (Tarraconensis), entre 9-10 d.C. Tácito não especifica quais foram as denúncias, contudo, possivelmente, elas incluíam acusações de repetundae (Ann. III 13). Vittelius, Veranius e Servaeus se ocupam das denúncias relacionadas às ações que visaram a recuperação da província da Síria $(A n n$. III 13, 2) e à morte de Germânico por envenenamento e sacrifícios (devotionibus et veneno), na qual estavam envolvidos Piso e sua esposa, Plancina.

Nos demais assuntos a defesa resultou convincente, pois não podia negar a complacência com os soldados e nem que a província estivera nas mãos de pessoas piores, que suas injúrias ao comandante. Apenas da acusação de envenenamento pareceu ter-se defendido [...] Mas os juízes se mostraram implacáveis por diversas razões: o César porque havia levado guerra a uma província; o Senado porque não podia crer que Germânico tinha morrido sem uma fraude [lacuna]. (Ann. III 14, 1-4).

Na ocasião da cremação de Germânico (Ann. II 73,4), Tácito aponta incertezas acerca da existência ou não de marcas que indicassem morte por envenenamento no corpo do falecido.

No trecho acima citado, apesar dos eventos ocorrerem na corte senatorial, observamos uma certa divisão entre o princeps e o Senado como juízes. Tibério centra a culpabilidade de $\mathrm{C} n$. Piso no seu levante pela reconquista da sua posição no comando da Síria. O Senado, por outro lado, não se mostrava convencido da inocência dos acusados em relação à morte de Germânico.

Logo, frente às provas e testemunhas apresentadas, a preocupação de Tibério se pautava em aspectos jurídicos, enquanto a atenção dos senadores era desviada para a punição dos responsáveis pela morte de Germânico, ainda que padecessem com a falta de provas para chegarem aos culpados. Essa atenção dada pelos senadores à morte de Germânico, de acordo com a narrativa taciteana, pode ser entendida a partir da intensa mobilização popular representada por esse historiador romano (Ann. II 82), além da culpabilidade de Tibério, sugerida pelo autor ao longo do Livro II e nos capítulos correspondentes a esse processo.

Cn. Piso suicidou-se antes do término do processo (Ann. III 15, 3). Sua esposa, Plancina, contando com o apoio de Lívia e de Tibério, segundo Tácito (Ann. III 15, 1; 17, 1) foi absolvida. M. Calpurnius Piso também foi absolvido, por intermédio da interferência de Tibério, (Ann. III 17, 1), da acusação de promover guerra civil.

Apesar do suicídio de $\mathrm{Cn}$. Piso, as acusações continuaram sendo discutidas na corte senatorial e contaram com a interferência significativa de Tibério. Não obstante Tácito tenha centralizado a descrição das ações em torno do princeps, ele também 
fornece indicativos que apontam para a existência de discordâncias e negociações entre senadores, Senado e o princeps.

Cabe também dizer que no decorrer dos capítulos nos quais descreve os eventos que levaram a acusação e o julgamento de $\mathrm{Cn}$. Piso, de sua esposa (Plancina) e de seu filho (M. Piso) não há nenhuma menção ao crimen maiestatis. No entanto, podemos inferir que este processo também abarcou uma acusação de maiestas com base nas denúncias apresentadas. As denúncias das ações de $\mathrm{Cn}$. Piso na Síria envolviam práticas criminalizadas pela Lex Cornelia de maiestate (81 a.C.). Esta lei, quando atrelada à Lex Cornelia de repetundis (81 a.C.), permitia a punição de más condutas jurídicas e militares de governadores provinciais. A Lex lulia de maiestate, possivelmente incorporou esses aspectos que permaneceram sendo empregados durante o Principado. Portanto, movimentar tropas sem autorização do Senado ou do imperador, fomentar a corrupção do exército e alimentar guerra civil, foram condutas atribuídas a Cn. Piso, julgadas e punidas de acordo com a Lex lulia de maiestate.

Além disso, na fala atribuída a Tibério, ele menciona que a excepcionalidade do caso estava relacionada ao envenenamento e à morte de Germânico. Assim, o que fez com que esse caso fosse julgado no Senado foram as denúncias em torno da morte do filho adotivo do princeps. Pois, nesse período denúncias relativas à más condutas dos governadores provinciais já eram apresentadas ao Senado, como o caso de $M$. Granius Marcellus (Ann. I 74), ocorrido em 15 d.C., e os posteriores casos de Caesius Cordus (Ann. III 38, 70) e C. Silanus (Ann. III 66-70), em 21 e 22 d.C. respectivamente; e de Fonteius Capito (Ann. IV 36), em 25 d.C.

Sobre as penalidades, Tácito nos conta que o então cônsul, Aurelius Cotta, propõe a retirada do nome de $\mathrm{Cn}$. Piso dos fasti, o confisco de parte dos bens deste e entrega da outra parte ao seu filho, Cn. Calpurnius Piso, que, por sua vez, deveria mudar de nome ${ }^{22}$. Aurelius Cotta também propõe que $M$. Piso perdesse a sua dignidade, que recebesse cinco milhões de sestércios e que fosse exilado (relegatio) por dez anos (Ann. III 17, 4). Tácito salienta que estas propostas foram suavizadas por Tibério.

O princeps suavizou esta proposta em muitos pontos: o nome de Piso não devia ser apagado dos fasti, visto que o de Marco Antônio, que havia empreendido guerra contra a res publica; e o de lullus Antonius, que havia desonrado a casa de Augusto, permaneciam neles. Além disso, salvou M. Piso da ignomínia e concedeu-Ihe os bens de seu pai [...] (Ann. III 18, 1).

Tácito (Ann. III 19,1) menciona que dias depois, Tibério propôs ao Senado que nomeasse ao sacerdócio os acusadores de $\mathrm{Cn}$. Piso pertencentes ao Senado, a saber: Vittelius, Veranius e Servaeus. Para Fulcinius Trio foi prometido o apoio do princeps nas eleições para as magistraturas. Trio já havia sido citado nos Anais como delator no processo de Libo Druso (Ann. II 27-32), em 16 d.C. "Era Trio célebre entre os acusadores por sua astúcia e sua avidez por má fama.” (Ann. II 28, 3). No que concerne à acusação de $\mathrm{C} n$. Piso, Tácito, apesar de ressaltar os benefícios alcançados através dessas denúncias, indica que para Tibério, naquele momento, tais práticas 
deveriam ser empregadas com cautela: “[...] a Fulcinius Trio prometeu seu apoio na eleição para honras, o aconselhou a não empregar sua eloquência em atitudes violentas." (Ann. III 19, 2).

Constatamos, em nosso levantamento dos processos judiciais correspondente aos anos entre 19-23 d.C., uma maior incidência de delatores nomeados na ocasião do relato da denúncia, quando comparado com os primeiros anos do governo de Tibério. Entre 14-18 d.C., identificamos seis delatores atuantes em casos de maiestas. A partir da acusação de $C n$. Piso, nos deparamos com quinze indivíduos citados como atuantes na instauração das denúncias.

Das denúncias descritas após o processo de Cn.Piso, Tácito também menciona duas condenações contra delatores por uma acusação indevida ${ }^{23}$. Assim, este historiador romano passa a discorrer sobre um breve período no qual Tibério, ao mesmo tempo que permaneceu interferindo na atividade judicial do Senado, passou a conter a ação dos delatores.

Esta inconstância nas decisões de Tibério também conduziu a narrativa do nosso autor a propósito da condenação, em 20 d.C., de Aemilia Lepida (Ann. III 22-23). De descendência ilustre ${ }^{24}$, após o seu divórcio de Publius Quirinus, Lepida foi acusada de adultério, de ter simulado o parto do seu filho com $P$. Quirinus e de ter consultado astrólogos sobre a família imperial (Ann. III 22, 1). A acusada foi defendida por seu irmão, Manius Aemilius Lepidus, cônsul em 11 d.C. Tácito nos diz que:

Não era possível perceber qual o pensamento de Tibério durante esse processo, tanto que ele inverteu e confundiu os sinais de ira e clemência. A princípio pediu ao Senado que não tomasse conhecimento do crimen maiestatis, depois incitou um dos cônsules, $M$. Servilius, e outras testemunhas a proferir o que ele tinha aparentado calar. (Ann. III 22, 2).

Até este momento, Tácito procurou retratar Tibério como um governante que procurava aparentar clemência em suas intervenções judiciais. Porém, por trás desta aparência, Tácito argumenta que o imperador regulava as ações apresentadas no Senado de modo a nortear quem seria punido ou inocentado. Por outro lado, para além da crítica expressa por Tácito, no trecho acima citado podemos vislumbrar um princeps que intentava não aplicar indiscriminadamente a Lex lulia maiestatis, tanto que, neste caso, a instauração foi realizada por um dos cônsules e não pelo princeps.

Aemilia Lepida foi condenada pela corte senatorial e exilada (aqua et igni interdictio), porém seus bens não foram confiscados (Ann. III 23, 2).

Druso, por sua vez, aparece na narrativa de Tácito como atuante, na qualidade de cônsul|25, na acusação (21 d.C.) de Annia Rufilla (Ann. III 36), instaurada pelo senador C. Cestius perante a corte senatorial. C. Cestius alegava que após ter conseguido a condenação de Annia Rufilla por fraude (Ann. III 36, 3), esta passou a direcionar ameaças contra ele no Fórum. Este senador dizia que ficou incapacitado de se defender contra as ofensas, pois a acusada trazia consigo uma imagem do imperador. A busca 
por asilo ou proteção em imagens imperais se justificava, uma vez que qualquer violência praticada contra o indivíduo portador da imagem era passível de acusação de maiestas. C. Cestius promoveu a denúncia perante o Senado alegando o uso indevido das imagens imperiais (Ann. III 36, 2-3). Druso determinou (Ann. III 36, 4) que ela fosse detida até ser julgada. Nada mais sabemos sobre a acusada e Tácito não nos forneceu o desfecho desse caso.

Outra denúncia desse período foi a acusação de adultério (21 d.C.) direcionada a Anitistius Vetus, nobre macedônico. O processo ocorreu perante a quaestio de adulteriis (Ann. III 38). Segundo Tácito, Tibério repreendeu a decisão dos juízes da quaestio e apresentou acusações de crimen maiestatis contra Anitistius Vetus.

Vale destacar que durante esses acontecimentos, Tibério não se encontrava em Roma e sim na Campânia, onde permaneceu entre 21-22 d.C. (Ann. III 31-64). Logo, toda comunicação com o Senado foi realizada nesse período através de cartas.

Ainda sobre o caso de Anitistius Vetus, após a sua absolvição pela quaestio de adulteriis, Tibério alegou que ele havia apoiado a sedição de Rhescuporis (Ann. II 6467) contra Roma. As informações proferidas sobre essa acusação não nos permitem afirmar em qual corte de justiça ela foi julgada. Tácito apenas nos diz que Anitistius Vetus foi condenado à interdição de água e fogo (aqua et igni interdictio), que, por sua vez, poderia ser consequência do exílio voluntário para um condenado a morte, pena esta que poderia ser determinada tanto pela quaestio maiestatis quanto pelo Senado. Todavia, a determinação de que este condenado deveria permanecer em uma ilha, sem acesso à Macedônia ou à Trácia, pode ser um indicativo de que a pena foi estabelecida pela corte senatorial, uma vez que, tal especificação não poderia ser realizada através dos procedimentos restritos de uma quaestio perpetua.

Este processo assinala como as acusações de maiestas e adultério eram utilizadas como estratégia para o afastamento de opositores políticos. Diferente de outros processos, a acusação de Anitistius Vetus ocorreu em duas frentes separadas, o que garantiu sua condenação e exílio. Também sinaliza para uma atuação dos juízes das cortes pretorianas, compostas por integrantes do album iudicium ${ }^{26}$, para além dos interesses imperiais. Assim, apesar de Tácito procurar destacar o crescimento da influência do princeps nas demandas judiciais na cidade de Roma, podemos vislumbrar certos indícios que apontam para um funcionamento das cortes de justiça públicas por vezes incongruente com as intenções atribuídas por Tácito a Tibério.

Em Ann. III 38 nos deparamos com a acusação, também em 21 d.C., de Caesius Cordus, antigo governador da província de Creta e Cirene: "Pois nem Tibério e nem os acusadores sentiam fadiga. Ancharius Priscus tinha denunciado Caelius Curso, procônsul de Creta, de repetundae, acrescentando a acusação de maiestas, que, então, era complemento de todas as acusações." (Ann. III 38).

Este período é descrito como um contexto no qual as acusações de maiestas passaram a complementar outras ofensas, promovendo o agravamento das denúncias e a distribuição dos benefícios oriundos do poder imperial aos delatores. Apesar deste contexto de favorecimento às denúncias de maiestas, a acusação de Caesius 
Cordus foi julgada apenas no ano seguinte, em 22 d.C. (Ann. III 70, 1). Os motivos para a demora na autorização e no julgamento da denúncia não foram explicitados por Tácito, assim como ele também não revelou a pena determinada pela corte senatorial pela condenação pelo crime de repetundae. O desfecho da acusação de maiestas não foi mencionado, o que pode sugerir que não houve condenação.

Outro acusado que teve sua denúncia de repetundae acrescida da acusação de maiestas foi C. Iunius Silanus (Ann. III 66-70), antigo governador da Ásia, província senatorial. Denunciado em 22 d. C. por repetundae pelos representantes da província, C. Silanus foi também acusado de maiestas por Mamercus Scaurus e lunius Otho, ambos senadores romanos; Bruttedius Niger, que ocupava o cargo de aedil; Gellius Publicola, questor do acusado durante seu proconsulado na Ásia, e M. Paconius, legado de Silanus (Ann. III 67, 1).

Logo passou-se paulatinamente da desonra para a hostilidade. C. Silanus, procônsul da Ásia acusado de repetundae por nossos aliados, lançaram contra ele Mamercus Scaurus, o pretor lunius Otho e o aedil Bruttedius Niger acusaram-no de ter profanado a divindade de Augusto [violatum Augusti numen] e de ter rejeitado a maiestas de Tibério. (Ann. III 66, 1).

O relato desse processo teve como mote principal a degradação, em razão do envolvimento em delações, de personagens oriundos de famílias ilustres ou que haviam construído suas carreiras políticas de modo exemplar. Para tanto, Tácito remonta à ancestralidade de Mamercus Scaurus, mostrando como este acusador a desonrava com suas delações. Sobre lunius Otho, antes responsável por uma escola (Ann. III 66, 2), afirma que ele havia se corrompido após ingressar no Senado, através do exercício da potentia de Sejano: "[...] se dedicava a desvincular suas origens obscuras com sua desavergonhada ousadia." (Ann. III 66, 3).

Na descrição desses três acusadores, Tácito nos oferece uma breve síntese da sua caracterização dos indivíduos que se beneficiavam das acusações de maiestas. Este historiador romano qualifica, ao longo do caso de $C$. Silanus, o acusador de origem ilustre, que difama seus antepassados atuando como delator, e aquele que usufrui dos benefícios promovidos pela potentia oriunda do imperador e que almeja o crescimento de sua carreira política através das delações. Sobre estes últimos, após se referir a Bruttedius Niger, Tácito declara: "[...] isto é algo que tem arrastado a perdição inclusive muitos homens honrados, que depreciando o progresso lento e seguro se precipitam ainda que isto os leve à ruína". (Ann. III 66, 4). Sabemos que Bruttedius Niger, possivelmente, foi punido após a morte de Sejano, em 31 d.C (WOODMAN; MARTIN, 1996, p. 463).

Tácito não questiona a culpa de C. Silanus: "Não havia dúvida de que Silanus era culpado de crueldade (saevitia) e repetundae, mas se acumulavam outras muitas circunstâncias perigosas, inclusive para pessoas inocentes." (Ann. III 67, 1-2).

Saevitia era um agravante que poderia acompanhar acusações de repetundae, como descrito por Plínio, o Jovem, no seu relato do processo no qual atuou, juntamente 
com Tácito, na acusação de repetundae (em 99-100 d.C.) que recaía sobre Marius Priscus, ex-procônsul da África (Ep. II 11, 2), perante a corte senatorial. Este agravante impedia o julgamento das acusações por uma comissão senatorial, que apenas poderia determinar a restituição dos valores extorquidos.

C. Silanus atuou na sua própria defesa, sendo inquirido arduamente por Tibério, segundo Tácito. Tibério solicita a leitura dos escritos de Augusto sobre Volesus Messala, procônsul da Ásia em 11 ou 12 d.C., e o senatus consultum com sua condenação. Posteriormente, Tácito passa a narrar o debate em torno da pena, sem mencionar se C. Silanus havia sido condenado apenas por repetundae ou também por maiestas. $\mathrm{O}$ argumento que reforça a hipótese de condenação apenas pelo crimen repetundarum é o de que não há indícios que informem que o julgamento de Volesus Messala, utilizado como precedente por Tibério para condenação de Silanus, envolveu crimen maiestatis, mas sim que foi agravado pela crueldade do acusado (SHOTTER, 1972, p. 129; WOODMAN; MARTIN, 1996, p. 466).

Ademais, a absolvição pelo crimen maiestatis também está de acordo com a atuação de Tibério nos demais casos que envolveram ações semelhantes às praticadas por C. Silanus. Por exemplo, M. Granius Marcellus (Ann. I 74) e Appuleia Varilla, (Ann. II 50) tiveram suas respectivas acusações agravadas em razão de iniuriae ${ }^{27}$ proferidas contra Tibério, porém apenas foram condenados por suas acusações iniciais repetundae e adultério, respectivamente - após solicitação do princeps para retirada das acusações de maiestas. Outro exemplo é a acusação de Rubrius (Ann. I 73), na qual ele foi denunciado por ter violado a divindade de Augusto, mas acabou sendo absolvido pela interferência de Tibério. Assim, apesar de não explicitar a absolvição de C. Silanus, concordamos com o estudioso Robert Samuel Rogers (1935, p. 67-68) quando este considera que a condenação foi em razão do crimen repetundarum. Para nós, esta é a possibilidade mais coerente dentro do contexto narrativo taciteano.

C. Silanus foi condenado ao exílio (relegatio) e enviado para ilha Cythnos (Ann. III 69, 5-6). Sua herança materna foi separada de seus bens e entregue ao seu filho (Ann. III 68, 2). Tácito não menciona o que houve com o restante dos bens, mas podemos supor, de acordo com os demais casos dessa natureza legados por nossa documentação, que eles foram utilizados no ressarcimento dos danos comprovados pelos representantes provinciais ou/e incorporados ao tesouro público romano.

Um último evento atrelado a este processo e que merece ser mencionado é a proposta de $P$. Cornelius Dolabella, senador que exerceu o consulado no mesmo ano (10 d.C.) que C. Silanus (SYME, 1986, p. 458). Cornelius Dolabella, procurando adular Tibério, propõe que nenhum homem que tenha sido manchado pela infâmia e vida vergonhosa participe dos sorteios realizados para indicação do senador que seria enviado como procônsul às províncias senatoriais (Ann. III 69) Acrescenta que o princeps deveria ser o responsável por julgar quem poderia ou não participar dos sorteios. Tibério, por sua vez, responde de modo contrário a esta proposta, argumentando que não se devia julgar com base em rumores. Tácito nos conta que Tibério argumentou que: 
Dizia que tão pouco o princeps podia abarcar com tudo e que não era conveniente que se deixasse levar por intrigas alheias. Que há uma razão pela qual as leis se estabeleciam frente ao passado: porque o futuro é incerto. Isto é o que havia sido, afirmava, a decisão dos maiores: que se havia, previamente, um delito a pena o seguiria. Os aconselhava a não alterar disposições tão sábias e que sempre haviam parecido oportunas. Muito peso também existia sobre o princeps, e também bastante poder [potentiae]: os direitos diminuíam onde os poderes [potestas] aumentavam e que não havia razão para usar o imperium quando se podia usar as leis. (Ann. III 69, 3-5).

Neste episódio, mais uma vez, nos deparamos com uma declaração de Tibério que vai ao encontro de uma perspectiva de compartilhamento de poder com Senado. Apesar de Tácito empregar essa fala de modo a denunciar as estratégias utilizadas para adulação e exaltação de Tibério, a resposta deste princeps é condizente com as ações relatadas por nosso autor, que apontam para existência de negociações entre o Senado e o poder imperial.

Outro caso que se adequa ao modelo intervencionista de Tibério, articulado por Tácito até este momento de sua narrativa em Anais, é a acusação de Lucius Ennius (Ann. III 70). De origem equestre, Lucius Ennius havia sido acusado de ter convertido uma estátua de Augusto em utensílios de prata. Tibério se opõe a instauração desta acusação, provavelmente fazendo uso do direito de veto (intercessio), ligado ao ius auxilii oriundo do poder tribunício (LEVICK, 1999, p. 239). Porém, encontrou a resistência de Ateius Capito:

\begin{abstract}
Alegava [Ateius Capito] que não devia tirar dos senadores o poder de tomar decisões e que um tal desaforo não poderia ficar impune. Se Tibério quisesse se mostrar brando em seu ressentimento próprio, dizia, mas que não fosse generoso com iniuriae contra a república. Tibério entendeu essas palavras mais como eram do que como se diziam e persistiu em seu veto. (Ann III 70, 2-3).
\end{abstract}

Tácito também relata a punição de dois delatores de origem equestre: Caelius Cursor e Considius Aequus (Ann. III 37,1). Ambos foram condenados, por iniciativa do Senado e do princeps, por terem apresentado acusação indevida de maiestas contra o pretor Magius Caecilianus. A pena imposta não foi especificada.

A condenação à morte de Clutorius Priscus (Ann. III 49-51) pelo Senado também pode ser vista como mais um momento no qual Tácito nos apresenta a orientação de Tibério, apesar deste ainda permanecer afastado de Roma, a partir das decisões da corte senatorial.

Clutorius Priscus foi acusado de ter escrito e proferido poema exaltando a doença de Druso, alegando que seria recompensado por Tibério, assim como fora na ocasião da morte de Germânico, quando foi gratificado por um poema escrito para o falecido. Em Anais, encontramos o debate no Senado em torno da pena estipulada. Clutorius 
Priscus foi aprisionado e em seguida executado. Tibério condena a pena imposta pelo Senado: "Tibério censurou esta ação com as ambiguidades de costume. Exaltou a piedade daqueles que castigam com as iniuriae contra o princeps, embora sejam pequenas, mas lamentou o castigo tão precipitado para umas palavras. (Ann. III 51, 1)"

Após a morte de Germânico, Tácito procurou descrever as atividades judiciais centradas no Senado, com forte presença e interferência de Tibério, além de uma crescente participação de Druso, como cônsul. Porém, ao ponderarmos sobre cada acusação perante a corte senatorial, foi possível identificar vestígios que nos apontam para negociações e embates entre senadores e o princeps. Além disso, cada vez mais, a figura do delator passou a compor os relatos dos processos de maiestas.

\title{
Acusações após a morte de Druso (23 d.C.)
}

Pouco antes de tratar da morte de Druso (Ann. IV 7; 8), Tácito discorre acerca das atividades e funções do Senado, destacando o compartilhamento das atribuições com Tibério.

\begin{abstract}
Me parece conveniente passar os olhos nos outros setores da res publica e nos modos pelos quais se desenvolveram até aquela data, visto que aquele ano [23 d.C.] supôs o começo de uma mudança para pior do Principado de Tibério. Em primeiro lugar, os assuntos públicos e os mais importantes assuntos privados eram tratados no Senado. Permitia aos mais nobres o debate, e o próprio Tibério colocava um fim a quem se deixasse arrastar para adulação. [...] Os cônsules conservavam sua aparência, assim como os pretores. Também se exercia a autoridade das magistraturas menores e as leis, se não considerada a de maiestas, tiveram bom uso. (Ann. IV 6, 1-3).
\end{abstract}

Esse panorama do governo de Tibério, apresentado por Tácito, vai ao encontro de nossa análise dos processos narrados até os eventos que ocasionaram a morte de Druso, em 23 d.C. Apesar desse historiador romano salientar diferentes ocasiões, em que senadores fizeram uso de estratégias adulatórias e o princeps impôs determinações ao Senado, foi possível verificar que mesmo nas acusações de maiestas, Tibério procurava dialogar com o Senado e aplicar as leis de acordo com os precedentes republicanos e de Augusto.

Contudo, Tácito nos indica que esse ambiente propício para o desempenho das magistraturas, das leis e para as atividades do Senado foi dissipado com a morte de Druso e o fortalecimento de Sejano.

[...] enquanto ele viveu [Druso] permaneciam tais princípios, porque Sejano, cujo poder [potentia] ainda estava no começo, queria fazer-se notar por sua bondade e conselhos e temia a vingança [de Druso], que não lhe ocultava o ódio, chegando a queixar-se repetidamente de que Tibério, tendo um filho vivo, chamara outro como auxiliar no império. (Ann. IV 7, 1). 
Tácito, no decorrer do Livro IV dos Anais, procurou insinuar o acirramento das acusações e o endurecimento dos julgamentos e das condenações. Também observamos o aumento dos relatos ligados às atividades judiciais de Tibério em sua corte de justiça.

Druso faleceu em 23 d.C., supostamente envenenado a mando de Sejano (Ann IV 8,1; 11). Com esta morte, Tibério não apenas perdeu seu filho, mas também mais um possível sucessor. A partir daí, passamos a observar em Anais uma presença cada vez maior da influência de Sejano, na época prefeito da guarda pretoriana, assim como uma crescente degradação e agressividade de Tibério.

Este processo de degradação foi atribuído por Tácito a Sejano, como observado por A. J. Woodman (2017, p. 309-310). As mortes de Druso e de Lívia (29 d.C.), membros da família imperial, influenciaram a atuação judicial de Tibério, assim como nas relações entre este princeps e o Senado. Nessa última parte do artigo, iremos nos dedicar aos casos que ocorreram entre a morte desses dois personagens, ou seja, entre 23-29 d.C.

Este recorte, apesar de se limitar ao Livro IV, conjuga o segundo maior número de $\operatorname{casos}^{28}$, atrás apenas dos anos finais do Principado de Tibério. Com isso, constatamos que Tácito utilizou da distribuição das denúncias de maiestas como estratégia para sua argumentação de degradação do governo deste princeps, como já anunciamos.

Outro recurso empregado foi a diminuição do espaço dedicado a cada caso, indicando o agravamento da perseguição política. Como destaca Bablitz (2015, p. 1718), o crescimento contínuo no número de casos por capítulo ao longo do Livro IV de Anais faz com que a audiência permaneça em constante contato com as acusações (BABLITZ, 2015, p. 18), como também sugere um permanente cenário de opressão e perseguição.

Tácito também procurou destacar o afastamento de Tibério dos precedentes de Augusto, como evidenciado no discurso de Cremutius Cordus (Ann. IV 34; 35). Cremutius Cordus foi acusado (25 d.C.) por Satrius Secundus ${ }^{29}$ e Pinarius Natta (ambos ligados por relações interpessoais com Sejano), de ter escrito uma história (annales ${ }^{30}$ ) na qual exaltava M. Bruttus e C. Cassius. Tácito destaca que a relação dos acusadores com Sejano e o olhar impiedoso de Tibério durante a sua defesa, fez com o acusado escolhesse a morte. $\mathrm{O}$ autor dos Anais descreve um discurso que Cremutius Cordus teria proferido antes de cometer suicídio. Nesta fala, o acusado teria procurado relacionar sua obra a outros textos semelhantes, datados do final da República (Ann. IV 34, 4-5) e do governo de Augusto (Ann. IV 34, 2-5). Com isso Cremutius Cordus procurou argumentar que as acusações dirigidas a ele não poderiam ser julgadas de acordo com a Lex Iulia Maiestatis.

Se acusam, padres conscritos, minhas palavras; até este momento sou inocente por minhas ações. Mas não se dirigem aquelas ao princeps, nem ao pai do princeps, aos quais abarca a lex maiestatis. Dizem que eu exaltei Brutus e Cassius, cujos feitos se muitos narraram, nenhum recordou sem honras. Tito Lívio, brilhante por sua eloquência e credibilidade, dirigiu tantos louvores a Cn. Pompeius que Augusto o chamava de pompeiano 
sem isso ter sido, no entanto, um obstáculo para amizade entre eles. (Ann. IV 34, 2-3)

Esse caso é amplamente estudado pela historiografia que se dedica a esse período em razão dos diversos aspectos que apontam para o posicionamento de Tácito perante o governo dos imperadores. Não podemos afirmar se o discurso, e inclusive o processo judicial, foram criações de Tácito (SYME, 1958, p. 512). No entanto, é consenso entre os pesquisadores que essa narrativa expressa a perseguição à liberdade e se configura como uma crítica deste historiador ao governo dos imperadores.

Outro aspecto observado é que parte significativa das acusações relatadas no Livro IV correspondem a ofensas praticadas nas províncias, como as denúncias contra Fonteius Capito (Ann. IV 36), C. Silius (IV 18-21), Sosia Galla (IV 18-22), Lucilius Capito (Ann. IV 15); Vibius Serenus (Ann. IV 28-30); Cn. Lentulus (Ann. IV 29); Seius Tubero (Ann. IV 29). Dentre todos os acusados citados nesse livro, apenas três foram absolvidos: Fonteius Capito, Carsidius Sacerdos e C.Gracchus. Apesar do elevado número de denúncias relativas às províncias, apenas os processos de $C$. Silius e Fonteius Capito apresentam indicativos de denúncia de repetundae. Ambos foram absolvidos do crimen repetundarum.

Além da grande quantidade de processos relativos às atividades romanas nas províncias e uma maior participação de Tibério como juiz, constatamos também o agravamento das condenações aplicadas nos processos relatados, e que se respaldavam em prerrogativas do Principado de Augusto, como acusações de adultério e inuria, acompanhadas de acusações de maiestas.

Nos livros anteriores, as denúncias de adultérios sediadas no governo de Tibério eram separadas das acusações de maiestas, com exceção do caso de Aemilia Lepida (Ann. III 22-24). Contudo, Livro IV, todas as acusações de adultério terminaram em condenações, independente do agravamento através da Lex maiestatis. Identificamos duas condenações por adultério, ambas julgadas em 26 d.C.: Aquilia (Ann. IV 42, 3), condenada ao exílio e a possível perda dos bens (WOODMAN, 2018, p. 231), e Claudia Pulchra (Ann. IV 52), que teve seu processo de adultério com Furnius atrelado à acusação de maiestas.

De acordo com nosso autor, essa denúncia deu início à perseguição contra Agripina, a Velha, neta de Augusto, viúva de Germânico e mãe do futuro imperador Calígula (sucessor de Tibério). Outros indivíduos próximos a Agripina e Germânico foram processados no decorrer do Livro IV, a saber: Sosia Galla (Ann. IV 18-21), seu marido C. Silius (Ann. IV 18-20) e Titius Sabinus (Ann. IV 68-70). O enredo das denúncias em torno dessa descendente de Augusto culminou na sua condenação e no seu exílio (Ann. V 3-5; VI 25).

É importante notar que nesse momento Tibério passa a associar as acusações de adultério e impudícia, ambas previstas na Lex lulia de adulteriis, à Lex lulia maiestatis, como previsto por Augusto. 
Além do adultério, as denúncias apresentadas contra Claudia Pulchra, como realizar sacrifícios e envenenamento, eram semelhantes às apresentadas pelos acusadores de Cn. Piso, denunciado pela morte de Germânico. No entanto, ao contrário deste último processo, Tácito não descreve os eventos que antecederam a denúncia de Claudia Pulchra, assim como dedica pouco espaço ao julgamento. Todo relato desse caso se centra na fala de Agripina, a Velha, em defesa de Claudia Pulchra (Ann. IV 52, 2), na arguição desta contra a perseguição de Tibério dos descendentes de Augusto, e na exaltação da oratória e prestígio do delator, Domitius Afer, ocasionados por suas ações judiciais (Ann. IV 52, 1, 4).

Claudia Pulchra e seu suposto cúmplice (Furnius) foram condenados. Contudo, Tácito não nos informa por quais crimes especificamente e quais foram as penas estipuladas. A omissão dessas informações é constante nos casos inseridos nos livros nos Livro IV-VI. Segundo Robin Seager (2005, p. 169), provavelmente, as acusações de maiestas foram abandonadas e Claudia Pulchra foi condenada apenas por adultério.

No ano seguinte, Quintilius Varus, filho de Claudia Pulchra com P. Quintilius Varus (Ann. I 3, 6) - cônsul junto com Tibério em 13 a.C. (WOODMAN, 2004, p. 03) - foi também acusado perante a corte senatorial (Ann. IV 66) por Domitius Afer e por $P$. Cornelius Dolabella.

Este caso é introduzido por uma reflexão do autor dos Anais acerca da crescente violência dos acusadores: "Mas se a diligência dos poderosos e a generosidade do princeps apoiavam o consolo às desgraças ${ }^{31}$, também a violência dos acusadores se fazia maior e mais danosa dia a dia, sem alívio." (Ann. IV 66, 1).

Desse modo, não apenas a atuação de Tibério na narrativa taciteana passou por modificações, como também a do Senado. As negociações acerca das denúncias e suas penalidades, sobre as quais discorremos cedem espaço a uma corte senatorial dependente das decisões imperais. O estudo aqui apresentado visou justamente explorar a dinâmica exposta por Tácito em sua obra, espaço onde associou o desempenho das atividades judiciais do Senado, enquanto corte de justiça, à atuação do imperador.

\section{Referências}

ALLISON, J. E.; CLOUD, J. D. The lex Julia Maiestatis. Latomus, v. 21, n. 4, p. 711-731, 1962.

BABLITZ, Leanne. Actors and audience in the Roman courtroom. London, New York: Routledge, 2007.

BABLITZ, Leanne. Tacitus on trial(s). In: BRICE, Lee L.; SLOOTJES, Daniëlle (Eds.). Aspects of ancient institutions and geography: studies in honor of Richard J. A. Talbert. 
Impact of Empire (Roman Empire, c. 200 B.C.-A.D. 476) (Series)Leiden, Netherlands: Brill, 2015. p. 65-83.

BAUMAN, Richard A. The crimen maiestatis in the Roman Republic and Augustan Principate. Johannesburg: Witwatersrand University Press, 1967.

CHILTON, C. W. The Roman Law of Treason under the Early Principate. Journal of Roman Studies, v. 45, n. 1-2, p. 73-81, 1955.

COWAN, Eleanor. Tacitus, Tiberius and Augustus. Classical Antiquity, v. 28, n. 2, p. 179-210, 2009.

DAMON, Cynthia. The Trial of Cn. Piso in Tacitus' Annals and the "Senatus Consultum de Cn. Pisone Patre": New Light on Narrative Technique. The American Journal of Philology, v. 120, n. 1, p. 143-162, 1999.

FLOWER, Harriet. Rethinking "Damnatio Memoriae": The Case of Cn. Calpurnius Piso pater in AD 20. Classical Antiquity, v. 17, n. 2, p. 155, 1998.

GOODYEAR, Francis Richard David. The annals of Tacitus: Volume II (Annals 1.55-81 and Annals 2). Cambridge: Cambridge University Press, 1981.

LEVICK, Barbara. Tiberius the politician. London, New York: Routledge, 1999.

ROGERS, Robert Samuel. Criminal trials and criminal legis/ation under Tiberius. Middletown: American Philological Association, 1935.

RUTLEDGE, Steven H. Delatores and the Tradition of Violence in Roman Oratory. The American Journal of Philology, v. 120, n. 4, p. 555-573, 1999.

SALLER, Richard. Personal patronagem under the early empire. Cambridge: Cambridge University Press, 1982.

SALLER, Richard. Patronage and friendship in early imperial Rome: drawing the distinction. In: WALLACE-HADRILL, Andrew (Ed.). Patronage in Ancient Society. London, New York: Routledge, 1990. p. 49-62.

SEAGER, Robin. Tiberius. Malden, Oxford, Carlton: Blackwell Publishing, 2005.

SHOTTER, David Colin Artur. The Trial of C. Junius Silanus. Classical Philology, v. 67, n. 2, p. 126-131, 1972.

SOUZA, Dominique Monge Rodrigues de. As cortes de justiça senatorial e imperial na cidade de Roma nos relatos de Tácito e de Plínio, o Jovem (séculos I-Il d.C.). 2019. Tese (Doutorado em História) - Faculdade de Ciências Humanas e Sociais, Universidade Estadual Paulista “Júlio de Mesquita Filho", Franca, 2019.

SYME, Ronald. Tacitus. Oxford: Oxford University Press, 1958. 
SYME, Ronald. The Augustan aristocracy. Oxford: Oxford University Press, 1986.

TALBERT, Richard J. A. The Senate of Imperial Rome. Princeton: Princeton University Press, 1984.

TALBERT, Richard J. Tacitus and the Senatus consultum de Cn. Pisone Patre. American Journal of Philology, v. 120, n. 1, p. 89-97, 1999.

WOODMAN, A. J. Translation, introduction and notes. In: TACITUS (Ed.). The Annals. Indianapolis: Hackett Publishing Company, 2004.

WOODMAN, A. J.; MARTIN, R. H. The annals of Tacitus: Book 3. Cambridge: Cambridge University Press, 1996.

WOODMAN, A. J.; MARTIN, R. H. Commentaries. In: TACITUS. The Annals of Tacitus: Books 5-6. Cambridge: Cambridge University Press (Cambridge Classical Texts and Commentaries), 2017.

WOODMAN, A. J.; MARTIN, R. H. The annals of Tacitus. Book 4. Cambridge: Cambridge University Press, 2018.

\section{Fontes}

PLINY. Letters and panegyricus. Translated by Betty Radice. Cambridge: Harvard University Press, 1969-1969. 2 v. (Loeb Classical Library).

TACITE. Annales. Text établi et traduit par Henri Goelzer. Paris: Societé d'édition "Les Belles Lettres", 1953. 3 v.

TÁCITO. Anales. Introducción, traducción y notas de José I. Moralejo, Madrid: Editorial Gredos, 1979-1980, (Biblioteca Clásica Gredos), 2 v.

TÁCITO. Anais. Trad. Leopoldo Pereira. São Paulo: Ediouro, s/d.

TACITUS. Annals. Translated by John Jackson. Cambridge, MA: Harvard University Press, 1931-1937. 3 v. (Loeb Classical Library).

TACITUS. The Annals. Translated, with introduction and notes by A. J. Woodman. Indianapolis, Cambridge: Hackett Publishing Company, 2004. 


\section{Notas}

10 presente artigo é derivado da tese de doutorado intitulada "As cortes de justiça senatorial e imperial na cidade de Roma nos relatos de Tácito e de Plínio, o Jovem (séculos I-II d.C.)", defendida no ano de 2019 no Programa de Pós-Graduação em História da Faculdade de Ciências Humanas e Sociais, Universidade Estadual Paulista “Júlio de Mesquista Filho”, UNESP-Franca.

2 Tribunais permanentes que possuíam uma jurisdição bem definida. Cada quaestio perpetua era responsável pelo julgamento de um único tipo de crime, considerado uma ofensa pública. Cada tribunal possuía um estatuto que definia as características das ações consideradas criminosas e que poderiam ser julgadas em determinada quaestio.

3 Há intensos debates entre estudiosos acerca da autoria, datação e conteúdo da Lex lulia de maiestate. A existência desta legislação pode ser atestada por sua menção em textos literários de autores como Cícero, Suetônio e Tácito, em comentários de juristas como os reunidos no Digesto 48. 4, dentre outras documentações. Porém, nenhuma das informações preservadas possibilitaram o estabelecimento de um consenso acerca da autoria e datação desta lei. Os embates buscam determinar se a Lex lulia de maiestate foi introduzida por César em 46 a.C. (ALLISON; CLOUD, 1962), ou por Augusto (CHILTON, 1955), ou se podemos afirmar a existência de duas legislações distintas (BAUMAN,1967, p. 278-281).

${ }^{4}$ M. Granius Marcellus (Ann. I 74); Cn. Calpurnius Piso (Ann. III 7-19); Caesius Cordus (Ann. III 38; 70); C. Silanus (Ann. III 66-69); Lucilius Capito (Ann. IV 15); C. Silius (Ann. IV 18-21) e Fonteius Capito (Ann. IV 36).

${ }^{5}$ Os gráficos apresentados nesse artigo foram elaborados pela autora com base no levantamento realizado nos Livros I-VI. Como critério para contagem dos processos narrados, consideramos apenas a primeira menção ao caso. Inserimos na contagem os casos cuja documentação explicitava a acusação e/ou condenação.

${ }^{6}$ Agrippa Postumus (Ann. I 6), exilado em 7 d.C. por motivos difíceis de serem precisados, desse modo, por não ser possível estabelecer as acusações direcionadas a ele, não incluímos em nosso recorte; Iulia (Julia, a Velha) (Ann. I 53; III 24; IV 71) e Sempronius Gracchus (Ann. I 53; III 24), ambos em 2 d.C., acusados de adultério e maiestas; e Cassius Severus (Ann. I 72) acusado de maiestas.

7 Falanius (Ann. I 73), Rubrius (Ann. I 73), M. Granius Marcellus (Ann. I 74).

${ }^{8}$ Apenas os primeiros capítulos do Livro $\vee(A n n . \vee 1-5)$ foram preservados. Os fragmentos não preservados corresponderiam a parte do ano de 29 d.C., 30 d.C. e 31 d.C.

9 Acusação de Libo Drusus (Ann. II 27-32) e de Appuleia Varilla (Ann. II 50).

10 Falanius e Rubrius (Ann. I 73); M. Granius Marcellus (Ann. I 74), respondeu apenas pela acusação de repetundae; Appuleia Varilla (Ann. II 50), respondeu apenas pela acusação de adultério.

11 Compreendemos relações interpessoais como as relações de amicitia e patronato. Nos respaldamos nas definições de Richard Saller (1982), presente em sua obra Personal Power under the early empire. Saller (1982, p. 01; 1990, p. 49) define o patronato como uma relação pessoal, o que a distingue de uma relação comercial, e que envolve trocas recíprocas; também é assimétrica, entre duas partes de status sociais diferentes. A assimetria é a principal característica que permitem a diferenciação entre a relação de patronato e a relação de amicitia, esta última se configurando como uma relação entre indivíduos de mesmo status social. Identificar estas relações na documentação nem sempre é uma tarefa simples, pois elas são expressas através de uma linguagem ambígua e fluída. Assim, devem-se observar os padrões de comportamento 
e convenções sociais expressos para a identificação de qual relação está sendo representada (SALLER, 1982, p. 11; 1990, p. 57).

12 Libro Drusus (Ann. II 27-32); Cn Calpurnius Piso (Ann. III 7-19); Plancina (Ann. III 8; 15; 17-19); C. Silanus (Ann. III 66-70); C. Silius (Ann. IV 18-21); Sosia Galla (Ann. IV 18-21).

13 Tácito possivelmente se valeu da acta senatus, registro dos procedimentos ocorridos no Senado, para composição de sua narrativa deste processo, assim como dos demais. Esta afirmação já era proclamada por especialistas (SYME, 1958, p. 283-284), mas foi reforçada com a divulgação para a comunidade acadêmica do Senatus Consultum de Cn. Pisone Patre (SCPP) (FLOWER, 1998, p. 158; TALBERT, 1984, p. 326-334; 1999, p. 89-90), na década de 90 do século passado.

14 Referência ao mar Adriático, segundo A. J. Woodman (2004, p. 61). Todavia, não se sabe ao certo quais eram as fronteiras para o exercício do imperium concedido pelo Senado a Germânico. O que sabemos é que o Egito não estava incluso nesse território, como Tácito nos informa em Ann. II 59.

15 Q. Caecilius Metellus Creticus Silanus, cônsul em 7 d.C. e procônsul da Síria de 12 d.C. até a nomeação de Cn Calpurinius Piso, em 17 d.C. Sua filha foi noiva de Nero Caesar, filho de Germânico com Agripina, a Velha (Ann. II 43, 2). (GOODYEAR, 1981, p. 324; SYME, 1986, p. 97).

16 Província romana localizada no sul da Ásia menor.

17 Inclusive, sinalizou que a substituição de Creticus Silanus por Cn. Piso no proconsulado da Síria, poderia estar relacionado com a aproximação de Silanus com Germânico através do noivado da filha do primeiro com Nero, filho de Agripina, a Velha, com Germânico (Ann. II 43, 2).

${ }^{18}$ Legatus Augusti (pro praetor) Hispanie (citerioris) (PIR $\left.{ }^{2} \mathrm{C} 287\right)$, governador da província imperial Hispania Citerior (Tarraconensis).

19 Cônsul em 1 a.C. (PIR² C 290). Em 24 d.C., foi acusado de maiestas (Ann. IV 21).

20 Sabemos apenas que foi cônsul em 18 a.C. (WOODMAN; MARTIN, 1996, p. 135).

${ }^{21}$ Cônsul em 6 d.C., influente senador romano, sendo inclusive citado por Augusto como possível sucessor, segundo Tácito (Ann. I 13, 2).

22 De acordo com SCPP (98-100), esta era a condição para que recebesse metade dos bens de seu pai. Assim, mudou o primeiro nome para Lucius (WOODMAN, 2004, p. 186).

${ }^{23}$ Acusação indevida de Magius Caecilianus (Ann. III 37).

${ }^{24}$ Bisneta de Pompeu e Sula (Ann III 22, 1).

25 Função exercida por ele pela segunda vez em 21 d.C. (Ann. III 31).

${ }^{26}$ Lista de jurados que poderiam ser convocados para julgarem processos nas cortes de justiça em Roma. Segundo Bablitz (2007, p. 92), sabemos que todos os membros do album deveriam ser cidadãos romanos com idade entre 25 e 60. Não era necessário nenhum treinamento jurídico, porém deveriam possuir bens dentro dos valores correspondentes a um dos seguintes níveis do censo: senatorial (1 milhão de sestércios), equestre (400 mil sestércios) ou ducenarii (200 mil sestércios).

27 Iniuria pode ser traduzida como “injustiça”, "prejuízo”, “injúria”, “ofensa” (FARIA, 1988, p. 280).

28 Identificamos trinta e um casos (gráfico 1), dos quais dezessete abarcam acusações de maiestas e/ou repetundae (gráfico 2 ). 
${ }^{29}$ Senador romano que denunciou a conspiração de Sejano, possivelmente relatado no fragmento perdido do Livro V. Satrius Secundus era casado com Albucilla, acusada e condenada por maiestas em 37 d.C., juntamente com diversos cúmplices (Ann. VI 47-48).

30 Este texto provavelmente abarcava o período da guerra civil republicana e o Principado de Augusto.

${ }^{31}$ Se refere, respectivamente, ao episódio no qual cidadãos ilustres abriram suas casas para receber os feridos no desabamento de um anfiteatro (Ann. IV 62;63) e à distribuição de donativos pecuniários por Tibério após um incêndio no monte Célio. (Ann. IV 64, 1).

\section{Declaração de Financiamento}

A pesquisa que resultou nesse artigo contou com o financiamento da Coordenação de Aperfeiçoamento de Pessoal de Nível Superior - Brasil (CAPES), código de financiamento 001, e da Fundação de Amparo à Pesquisa do Estado de São Paulo (FAPESP), processo n 2015/07270-9.

Dominique Monge Rodrigues de SOUZA. Doutora em História. Professora da Secretaria de Educação do Estado de São Paulo e pesquisadora do Grupo do Laboratório de Estudos sobre o Império Romano (G.LEIR, UNESP/FRANCA), Universidade Estadual Paulista, Faculdade de Ciências Humanas e Sociais - UNESP, campus Franca, São Paulo, Brasil.

\section{Editores}

